\title{
The Research on the Moderating Role of Structural Hole between Perceived Value and Purchase Intention
}

\author{
Shao Jing-bo \\ School of Management, Harbin Institution of Technology \\ Room 330, Building 2H, Science Park, Number 2, Yikuang \\ Street, Nangang District, Harbin, China \\ boboshao@163.com
}

\author{
Yao Fei-si \\ School of Management, Harbin Institution of Technology \\ Room 347, Building 2H, Science Park, Number 2, Yikuang \\ Street, Nangang District, Harbin, China \\ yaofeisihit@163.com
}

\begin{abstract}
The relationship between customer perceived value and purchase intention has been explored among scholars for many years. However, it is still blurry that when the relationship is stronger and when is weaker. Our study fills the gap by integrating the structural hole theory into the relationship and exploring the moderating effect of structural hole on the relationship between perceived value and purchase intention. Using the data of $\mathbf{3 0 5}$ college students and employees in China, and via SPSS and Amos, the current research finds that the relationship between customer perceived value and purchase intention tends to be significantly stronger with the increasing of structural hole. While with the decreasing in structural hole, the nexus between perceived value and purchase intention would become weaker. Our study finds the boundary condition in the relationship between perceived value and purchase intention. Specific theoretical and practical implications of the results are discussed at the remainder.
\end{abstract}

Keywords-customer perceived value; purchase intention; structural hole; moderating role

\section{INTRODUCTION}

To survive in the fierce voluntary market, Companies make great efforts to enhance customer's perceived value which is pearl to attract and retain customers. Born in the 1990s, customer perceived value is still pivotal nowadays [1], which will facilitate many customer behavior factors such as customer satisfaction [1], customer loyalty [2], as well as customer purchase intention $[1,3,4]$.

Though vast studies abound with the positive relationship between customer perceived value and purchase intention, the intensity of the relationship is different [3-4]. Combing through substantial research, this study invites structural hole, which is understood as a gap between two distinct individuals [5], as the moderator. Three reasons are following regarding why we choose this variable.

Firstly, all individuals are social animals and need to interact with different people and exchange various information, which means people are all embedded in their own social networks and inevitably affected by their social network [6]. Especially with the burgeoning of Internet, social influence within the network has imperceptibly permeated into buying process and acts a critical role in product demand [7]. Recently, it is revealed that weak ties among social network tend to elevate the positivity of information shared [8]. Existing research have shown exposure to positive product information plays a critical role in consumer purchase probability [9-10]. Thus, we suppose that based on weak ties, structural hole theory which is as an important theory of social network, may also facilitate the spread of positive product information and ultimately boost purchase intention.

Secondly, the structural hole theory demonstrating the nonredundant relationship between two individuals, the application of structural hole in marketing is still sparse but in bud [11] and the dimensions of social network (e.g. network centrality, tie strength, etc.) as moderator has lingered for a few years [12]. As an indispensable part of social network, structural hole has already been treated as antecedent [13] and result variable [11]. Thus, we assume that structural hole would moderate the relationship between customer perceived value and purchase intention.

Accordingly, the objective of this study is to investigate how structural hole - the moderator influences the relationship between customer perceived value and purchase intention. Our research provides three contributions to customer perceived value and purchase intention literature. First of all, we mined the frontier between customer perceived value and purchase intention, which will interpret why the intensity of the positive relationship is a bit different in various occasions and flesh out the relationship. Furthermore, we expanded the application as we treated structural hole as the moderator in marketing area. And our study reaches a reasonable result from the perspective of positive product information. Finally, this research also extends the application of the structural whole theory from enterprise level to customer level. Whereas prior work has mainly identified the role of structural hole in firms, the present findings show when structural hole influence customer behavior more strongly. 


\section{THEORY AND HYPOTHESIS}

\section{A. Customer Purchase Intention}

Intention is the subjective probability of someone taking specific actions and is also the essential process before any actions [14]. In terms of literal meaning, customer purchase intention is obviously a kind of intention. According to Dodds and Grewal (1991), customer purchase intention is their willingness to buy. Thus, customer purchase intention plays a pivotal role in customer's decision to buy a certain product.

Vast researches have already dug into the influential factors of purchase intention. Among the prior studies, there exists three mains angles which are firms, products, brands, and customers themselves.

\section{B. Customer Perceived Value and Customer Purchase Intention}

Across a broad spectrum of research, various expressions (e.g. customer value; perceived value; perceived customer value) similar to customer perceived value as for appearance are indicated the same concept [15]. Customer perceived value, as defined in this research, is the balance between quality and price.

There are several reasons to believe that customer perceived value and purchase intention have worked 'hand in glove' for many years. A person's buying intention will be anticipated from the person's overall perception of quality [16] Therefore, we make the following hypothesis:

Hypothesis 1a: Perceived price/value for money function value is positively related with purchase intention.

Hypothesis 1b: Perceived performance/quality function value is positively related with purchase intention.

\section{Structural Hole}

The concept of structural hole was pioneered by Burt (1992) in his book, in which he argues that the maintenance of intraorganizational communication network links providing the opportunities to propagate information more freely and efficiently through a network. These connections are well known as structural hole bridges. The theory of structural hole indicates that individuals would take the advantage of taking the 'hole' position. People whose networks span various structural holes are more likely to hand in resources like compensation, positive performance evaluations, promotions, and good ideas to different extent.

In our study, the individual holding more structural holes could access and retain more positive product information from others. As the degree of coherence between the product information obtained and the information held by the customer is increased, customer who already has perceived value of that product would show a corresponding increase of confidence in that product [17] and ultimately instrumental in purchase intention. In other words, the interplay of customer perceived value and the richness of structural hole would influence purchase intention. The individuals enjoying more structural holes would have more chance to receive positive product information and then the correlation of customer perceive value and purchase intention would be stronger. As a result, we postulate the following hypothesis:

Hypothesis2a: The positive relationship between perceived price/value for money function value and purchase intention is enhanced with the increase of structural hole.

Hypothesis2b: The positive relationship between perceived performance/quality function value and purchase intention is enhanced with the increase of structural hole.

\section{RESEARCH DESIGN}

Actually, the PREVAL scale entails four dimensions which are emotional value, social value, price/value for money function value and performance/quality functional value. As the definition of customer perceived value applied in our research brought out by Monroe (1990) only includes the two function value, we followed the PREVAL scale accordingly exclusive of emotional value and social value.

What we want to note is that in the original scale of customer perceived value, there exists another item '.. has poor workmanship'. However, when we translated the item into Chinese, this item has the same meaning of the item '.. is well made' with the converse expression means. So, the item '... has poor workmanship' is eliminated in our research correspondingly.

\section{A. Data and Sample}

Our questionnaires covered responses in the college campus as well as prosperous commercial center, 305 of which remained for analysis after removing invalid responses. Overall, $46.9 \%$ of the respondents were male and the rest was female. Most of the respondents were young, with an average age of 27.14 (s.d. = 8.60). The reasons why we choose Mac as our research product are that Apple's products are pretty omnipresent in China nowadays and Mac is supposed to be a customer durable good relative to iPhone and iPad. The questionnaire is composed of four parts. The first involved questions measuring basic characteristics of the survey subjects. The second embraced questions concerning the items of customer perceived value. The third part contained questions pertinent to customer purchase intention. And the last part included the questions relating to the variables of structural hole.

Unless specially noted, all of the scales were translated from English to Chinese according to the standard of translation and back-translation. Five-point Likert-type scales ranging from 1 ('strongly disagree') to 5 ('strongly agree') were used in the study of customer perceived value and structural hole, while seven-point Likert-type scales between 1 ('strongly disagree') and 7 ('strongly agree') is applied in the test of customer purchase intention. All of the scales had adequate reliability, as shown in TABLE I.

\section{B. Exploratory Factor Analysis and Reliability}

As shown in TABLE I, the overall reliability for each construct is good except for structural hole. The reliability of structural hole is relatively lower than others. Casting on the item NSH3 and NSH4 and after deleting them the Cronbach's 
alpha for the whole measurement reliability has been significantly improved. Nevertheless, whether to discard the above-mentioned items dependent on the validity analysis. The KMO value and significance of the Bartlett test is suitable enough to carry out the factor analysis of which the result is indicated in TABLE II. From TABLE II, we could easily see that four principal components extracted are consistent with the constructs, which means the scale enjoys good validity. Plus, four principal components explain $66.845 \%$ of total variance. Due to the fact that the contribution of NSH3 and NSH4 is trivial and considering the reliability analysis, we abandoned these two items.

TABLE I EXPLORATORY FACTOR ANALYSIS RESULTS

\begin{tabular}{cccc}
\hline Variables & $\begin{array}{c}\text { Cronbach's } \\
\text { alpha }\end{array}$ & Items & $\begin{array}{c}\text { Cronbach's alpha if } \\
\text { item deleted }\end{array}$ \\
\hline Perceived functional & & FV11(Q) & 0.863 \\
value1 (Quality) & 0.813 & FV12(Q) & 0.869 \\
& & FV13(Q) & 0.867 \\
& FV14(Q) & 0.881 \\
FV15(Q) & 0.869 \\
\hline value2 (Price) & \multirow{2}{*}{0.859} & FV21(P) & 0.873 \\
& & FV22(P) & 0.866 \\
Customer purchase & \multirow{3}{*}{0.953} & FV24(P) & 0.862 \\
intention & & CPI1 & 0.869 \\
\hline & & CPI3 & 0.857 \\
Network structural & \multirow{2}{*}{0.420} & CPI4 & 0.857 \\
hole & NSH1 & 0.858 \\
& & NSH3 & 0.858 \\
\hline
\end{tabular}

TABLE II ROTATED COMPONENT MATRIX

\begin{tabular}{lcccc}
\hline \multicolumn{1}{c}{ Items } & F1 & F2 & F3 & F4 \\
\hline 11(Q) & .598 & .131 & .547 & .037 \\
FV12(Q) & .486 & -.064 & .679 & .085 \\
FV13(Q) & .500 & -.009 & .664 & .074 \\
FV14(Q) & -.005 & .017 & .649 & .063 \\
FV15(Q) & .390 & .116 & .586 & -.027 \\
FV21(P) & .192 & .821 & -.117 & .009 \\
FV22(P) & .364 & .735 & .048 & .089 \\
FV23(P) & .390 & .660 & .284 & .041 \\
FV24(P) & .251 & .838 & -.033 & -.024 \\
CPI1 & .807 & .275 & .248 & .041 \\
CPI2 & .861 & .313 & .100 & -.031 \\
CPI3 & .846 & .344 & .060 & -.105 \\
CPI4 & .871 & .277 & .065 & -.043 \\
NSH1 & -.040 & .003 & .138 & .875 \\
NSH2 & -.049 & .063 & -.007 & .865 \\
NSH3 & -.056 & .347 & .289 \\
NSH4 & .387 & .392 & -.245 \\
\hline & & & & \\
\hline
\end{tabular}

\section{RESULTS}

The test result for Hypothesis 1 is shown in TABLE IV. According to TABLE IV, it is apparent that perceived price/value for money function value and performance/quality functional value both positively relate to customer purchase intention $(\beta \mathrm{Q}=.536, \beta \mathrm{P}=.411 \mathrm{p}<0.05)$. Therefore, hypothesis $1 \mathrm{a}$ and hypothesis $1 \mathrm{~b}$ are supported.

TABLE III GRESSION ANALYSIS RESULTS

\begin{tabular}{lllrc}
\hline Paths & Direction & Variables & Estimated value & $\begin{array}{c}\text { Standard } \\
\text { deviation }\end{array}$ \\
\hline CPI & $<-$ & NSH & $-.482^{* * *}$ & .065 \\
CPI & $<-$ & FV1 & $.536^{* * *}$ & .071 \\
CPI & $<-$ & FV1 $\times$ NSH & $.018+$ & .010 \\
CPI & $<-$ & FV2 & $.411^{* * *}$ & .063 \\
CPI & $<-$ & FV2 $\times$ NSH & $.024 *$ & .012 \\
\hline
\end{tabular}

a. Note: *** Significant at $\mathrm{p}<.001, * *$ Significant at $\mathrm{p}<0.01,{ }^{*}$ Significant at $0.05,+$ Significant at $\mathrm{p}<.1$.

Based on Robert Ping (1995)'s parsimonious estimating technique, we created two interactions in the SEM to validate the moderation role of structural hole. Reassuringly, hypothesis $2 \mathrm{a}$ and $2 \mathrm{~b}$ have been verified via AMOS, which means the structural hole does moderate the relationship between perceived value and purchase intention.

To further examine Hypothesis 2, we constructed FIGURE II and FIGURE III according to two levels of structural hole. As illustrated in FIGURE II, when the level of structural hole was high, the relationship between perceived price/value for money function value and purchase intention was enhanced, and when the level of structural hole was low, the relationship between perceived price/value for money function value and purchase intention was mitigated.

As illustrated in FIGURE III, when the level of structural hole was high, the relationship between perceived performance/quality function value and purchase intention was enhanced, and when the level of structural hole was low, the relationship between perceived performance/quality function value and purchase intention was mitigated.

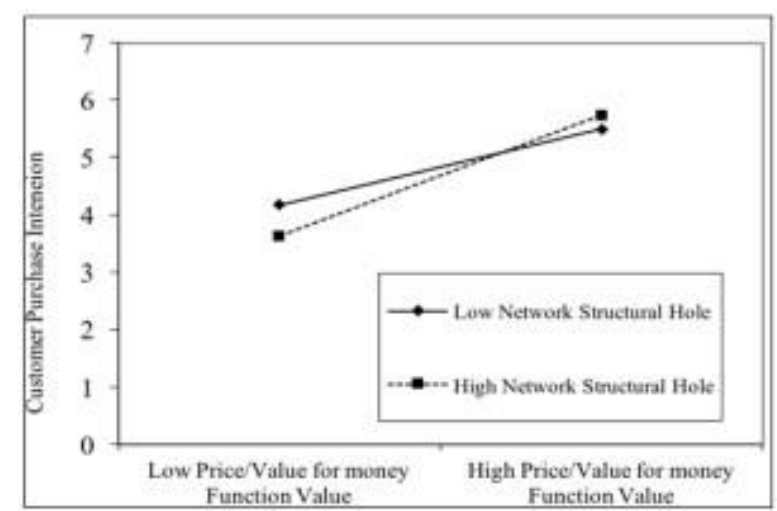

Fig. 1. FIGURE II. RELATIONSHIPS BETWEEN PRICE/VALUE FOR MONEY FUNCTION VALUE AND CUSTOMER PURCHASE INTENTION AS A FUNCTION OF NETWORK STRUCTURAL HOLE 


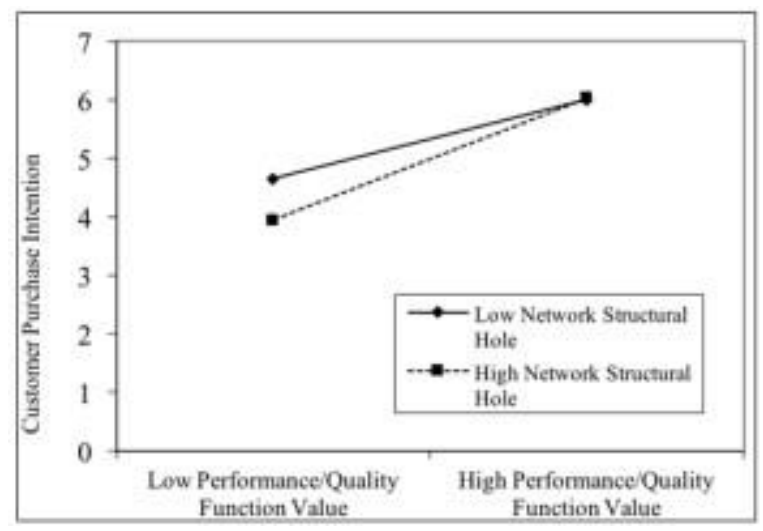

Fig. 2. RELATIONSHIPS BETWEEN PERFORMANCE/QUALITY FUNCTION VALUE AND CUSTOMER PURCHASE INTENTION AS A FUNCTION OF NETWORK STRUCTURAL HOLE

In this article, we depict the moderate effect of structural hole on the relationship between customer perceived value and purchase intention. The results of our statistics analysis illuminate that Price/Value for money Function Value would more prompt the likelihood to buy when the structural hole level is high. As well, the structural hole level also shows the similar impact on the nexus between Performance/Quality Function value and purchase intention. Both the study results are consistent with our prediction.

\section{Theoretical Implications}

Our findings further the relationship between customer perceived value and purchase intention. However, there has been few research investigating when customer perceived value will have a stronger positive impact on purchase intention. The current research identified a favourable boundary condition from novel perspective of the structural hole theory.

Our work contributes to the structural hole literature by recognising it as a moderator. The structural hole theory actually has been introduced into the customer research for a few years. However, most of the researches treated the structural hole as independent variable and hasn't brought out favourable research results. Our study puts the structural hole in the moderator position and reaches a reasonable result from the perspective of need.

This research also extends the application of the structural hole theory from enterprise level to customer level. As an important branch of social network, the structural hole theory has received great attention for decades since it was born. However, the main research focus of the structural hole theory has been tightly related to enterprise turnover, social capital, performance, innovation and productivity [18]. Although few researches has turned the attention from enterprise to individual, most of them has been linked to individual personality and how individuals hold the structural hole position. The current research contributes to the previous literature by demonstrating the moderator role of structural hole based on the customer social network.

\section{Limitations}

Our study has several limitations that should be addressed in the future research. First, our study examined the relationships among variables based on a cross-sectional design, so we cannot rule out the possibility of alternative pathways and feedback loops. Second, the ratings of independent variables, dependent variables and moderators used in this study were all provided by college students and general customers, and it is possible that these results were influenced by common source variance [19]. We adopted an inversion of items to measure variables, which helped to control for common source variance, but only to a limited degree. Third, the subjected item in the current research is Macbook and whether the study effect is able to replicate in other items still needs future studies to confirm our findings. Forth, there are manifold definitions of customer perceived value and different definitions have different dimensions. We only selected a twodimensional definition from various literature and whether our study results still hold for other multidimensional definitions of customer perceived series enjoys relatively high price among various computers in China. According to the previous inference, Chinese people may think Macbook endowed with higher quality than others and thus it is more likely for them to purchase.

\section{PRACTICAL IMPLICATIONS AND CONCLUSIONS}

This research has important implications for enterprises and marketing managers. Our study indicates that the relationship between customer perceived value and customer purchase intention depends on the extent of structural holes. Marketing managers could increase the purchase possibility of individuals enjoying various structural holes by online advertisements via e-mails or imessages or mobile notification and setting the advertisements from the perspective of their fundamental needs. What's more, customers who have abundant structural holes may have the opportunity to communicate and get acquaintance with different people from different occupations, which means they may serve as a demonstration and recommendation after they buy the related articles.

\section{ACKNOWLEDGMENT}

This work was supported by <the National Natural Science Foundation of China > under Grant [number 71672048, 71172155]; <the Fundamental Research Funds for the Central Universities> under Grant [number HIT.HSS.201104].

\section{REFERENCES}

[1] R. Kisang, L. Hyerin, and K.Woogon, "The influence of the quality of the physical environment, food, and service on restaurant image, customer perceived value, customer satisfaction, and behavioral intentions." International Journal of Contemporary Hospitality Management, vol. 2, pp.200-223, 2012.

[2] Z. Yang and R.T. Peterson, "Customer perceived value, satisfaction, and loyalty: the role of switching costs.” Psychology and Marketing, vol.21, pp.799-822, 2004. 
[3] R.Tsiotsou, "The role of perceived product quality and overall satisfaction on purchase intentions." International journal of customer studies, vol.30, pp. 207-217, 2006.

[4] J. Beneke, R. Flynn, T. Greig, and M. Mukaiwa, "The influence of perceived product quality, relative price and risk on customer value and willingness to buy: a study of private label merchandise." Journal of Product and Brand Management, vol.22, pp.218-228, 2013.

[5] R. S. Burt, Structural hole, Harvard Business School Press: Cambridge, MA, 1992.

[6] J. B. Shao, K. K. Chen, and A. M. Wu, "Research on the influence of customer network characteristics on customer relationship value under B-C environment-empirical study in service industry." Forecasting, vol.33, pp. 27-32, 2014.

[7] S. Aral and D. Walker, "Tie strength, embeddedness, and social influence: a large-scale networked experiment." Management Science, vol.60, pp. 1352-1370, 2014.

[8] D. Dubois, A. Bonezzi, and M.A.T.T.E.O. De Angelis, "Sharing with friends versus strangers: how interpersonal closeness influences wordof-mouth valence.” Journal of Marketing Research, vol.53, pp. 712-727, 2016.

[9] R. East, K. Hammond, and W. Lomax, "Measuring the impact of positive and negative word of mouth on brand purchase probability." International journal of research in marketing, vol.25, pp. 215-224, 2008

[10] J.G. Maxham, "Service recovery's influence on consumer satisfaction, positive word-of-mouth, and purchase intentions." Journal of Business Research, vol.54, pp. 11-24, 2001.

[11] Z. M. Zhou, Q. Q. Deng, and Z. J. Rao, "Product knowledge and structural hole in online brand communities: the moderation of interdependent self.” Journal of Management Science, vol.28, pp. 86-96, 2015.

[12] G. Hoye, E. A. Hooft, and F. Lievens, "Networking as a job search behaviour: a social network perspective." Journal of Occupational and Organizational Psychology, vol.82, pp. 661-682, 2009.

[13] G. Walker, B. Kogut, and W. Shan, "Social capital, structural holes and the formation of an industry network." Organization science, vol.8, pp. 109-125, 1997.

[14] M. Fishbein and T. Azjen Belief, "Attitude, intention, and behavior: an introduction to theory and research." Research, 1975.

[15] R. Sánchez-Fernández and M.Á. Iniesta-Bonillo, "Consumer perception of value: literature review and a new conceptual framework." Journal of Consumer Satisfaction, Dissatisfaction and Complaining Behavior, vol.19, pp. 40-58, 2006.

[16] W. Boulding, "A dynamic process model of service quality: from expectations to behavioral intentions." Journal of marketing research, vol.30, pp. 7-27, 1993.

[17] R. Bhargave, A. Mantonakis, and K. White, "The cue-of-the-cloud effect: when reminders of online information availability increase purchase intentions and choice." Journal of Marketing Research, vol.53, pp. 699$711,2016$.

[18] A. Zaheer and G.G. Bell, "Benefiting from network position: firm capabilities, structural holes, and performance." Strategic management journal, vol.26, pp. 809-825, 2005.

[19] P.M. Podsakoff, S.B. MacKenzie, J.Y. Lee, and N.P. Podsakoff, "Common method biases in behavioral research: a critical review of the literature and recommended remedies." Journal of applied psychology, vol.88, pp. 879-903, 2003. 